\title{
ANALISIS MISKONSEPSI SISWA PADA MATERI DINAMIKA GERAK MENGGUNAKAN TES DIAGNOSTIK PILIHAN GANDA TIGA TINGKAT
}

\author{
Sitri Wuryanti ${ }^{1)}$, Yennita $^{2)}$, Fakhruddin $^{3)}$
FKIP Universitas Riau \\ e-mail: sitriwuryanti36@gmail.com \\ yennita_caca@yahoo.com \\ faruqfisika@yahoo.com
}

\begin{abstract}
Abstrak
Penelitian ini bertujuan untuk mengetahui tingkat miskonsepsi siswa pada materi dinamika gerak. Adapun subjek pada penelitian ini adalah seluruh siswa kelas XII SMA Negeri Plus Provinsi Riau yang berjumlah 85 siswa. Jenis penelitian yang digunakan adalah penelitian survei. Data penelitian diperoleh dari hasil pemberian tes diagnostik pilihan ganda tiga tingkat (three-tier multiple choice) yang berjumlah 30 butir soal. Analisis data dilakukan menggunakan teknik analisis deskriptif. Hasil penelitian menunjukkan bahwa ratarata persentase siswa yang mengalami miskonsepsi pada setiap materi pokok adalah 57.01\% untuk gaya dan hukum-hukum Newton, 69.02\% untuk hukum Newton tentang gravitasi, 49.18\% untuk usaha dan energi, 48.24\% untuk elastisitas dan hukum Hooke, 59.77\% untuk momentum, impuls, dan tumbukan serta 41.47\% untuk keseimbangan dan dinamika rotasi. Secara umum, rata-rata persentase siswa yang mengalami miskonsepsi pada materi dinamika gerak adalah sebesar $54.71 \%$. Dengan demikian dapat disimpulkan bahwa tingkat miskonsepsi yang dialami siswa kelas XII SMA Negeri Plus Provinsi Riau pada materi dinamika gerak berada pada kategori sedang.
\end{abstract}

Kata kunci: dinamika gerak, miskonsepsi, tes diagnostik pilihan ganda tiga tingkat

\begin{abstract}
This study aimed to know students' misconception level on dynamic motion. The subject of this research was all students of XII grade students at SMA Negeri Plus Provinsi Riau with the number were 85 students. It was a survey research. The research data was obtained from the result of three-tier multiple choice diagnostic test with the number of questions were 30 items. Data was analyzed using descriptive analysis techniques. The research result showed that the average of percentage's students those had misconception on each submaterial were 57.01\% for Force and Newton Law, 69.02\% for Newton's Law on Gravity, 49.18\% for Work and Energy, 48.24\% for Elasticity and Hook's Law, 59.77\% for Momentum, Impulse, and Collision, and $41.47 \%$ for Equilibrium and Rotational Dynamic. Generally, the students' average of percentage those had misconception on dynamic motion was 54.71\%. Therefore, it can be conclude that misconception level of XII grade students at SMA Negeri plus Provinsi Riau on dynamic motion is on the middle level.
\end{abstract}

Keywords: dynamic motion, misconception, three-tier multiple choice diagnostic test 


\section{Pendahuluan}

Menurut Kamus Besar Bahasa Indonesia (KBBI) konsep diartikan sebagai ide atau pengertian yang diabstrakkan dari peristiwa konkret. Sebelum memasuki fase pembelajaran di sekolah, siswa telah memiliki suatu keyakinan terhadap terjadinya suatu hal, konsep-konsep dan ekpektasi yang dapat membantu dalam memprediksi sesuatu yang akan terjadi (Oberoi, 2017). Seorang anak mengembangkan ide-ide dan keyakinannya melalui pengalaman dikehidupan sehari-hari, baik dari apa yang dirasakan, bahasa seharihari, latar belakang kebudayaan, teman bermain seperti sebuah instruksi formal (Tuysuz, 2009). Terkadang konsep-konsep yang diyakini oleh siswa tidak sesuai dengan konsep yang diakui oleh para ahli, fenomena ini disebut miskonsepsi (Paul Suparno, 2013).

Asep Dedy Sutrisno (2014) mengatakan bahwa fisika merupakan mata pelajaran yang mempunyai konsep bersyarat untuk setiap jenjang materi. Pada umumnya kesulitan yang dialami siswa dalam mempelajari fisika disebabkan ketidakmampuan siswa dalam menghubungkan materi yang sedang dipelajari dengan pengetahuan yang dimiliki (Luh Sukariasih, 2016). Ketidakmampuan siswa ini dapat disebabkan karena pengetahuan yang dimiliki siswa tidak sesuai dengan konsep yang sebenarnya. Dengan kata lain miskonsepsi siswa terhadap suatu konsep dapat menghambat siswa tersebut dalam mempelajari konsep yang baru (Dindar dan Geban, 2011).

Oleh sebab, itu miskonsepsi perlu untuk segera diatasi. Namun sebelum memasuki tahapan tersebut, terlebih dahulu harus dilakukan identifikasi pada bagian mana saja siswa mengalami miskonsepsi. Untuk mengidentifikasi miskonsepsi dapat dilakukan dengan tes diagnostik. Bruckner dan Melby dalam Suwarto (2013) menjabarkan bahwa tes diagnostik merupakan tes yang digunakan untuk menentukan elemen-elemen dalam suatu mata pelajaran yang mempunyai kelemahankelemahan khusus dan menyediakan alat untuk menemukan penyebab kekurangan tersebut.

Three-tier test yang dikembangkan oleh Pesman dan Eryilmas (2010) merupakan salah satu bentuk tes diagnostik yang digunakan dalam mendeteksi miskonsepsi, yaitu berupa rangkaian soal yang terdiri dari tiga tingkatan. Tingkat satu berupa soal pilihan ganda biasa, tingkat dua berisi pertanyaan dengan pilihan alasan untuk soal pada tingkat pertama, disediakan pula tempat yang kosong untuk menuliskan alasan secara bebas. Pada tingkat tiga, disajikan pertanyaan penegasan keyakinan siswa dalam menjawab soal pada dua tingkatan sebelumnya.

Salah satu pembahasan dalam pelajaran fisika dimana siswa sering mengalami miskonsepsi adalah pada bidang mekanika (Izza Auliyatul Muna, 2015). Pada bidang mekanika terdapat suatu sub pembahasan yaitu dinamika yang menjelaskan tentang penyebab benda-benda bergerak. Pembahasan ini sangat penting dalam mekanika dan seringkali berhubungan erat dengan materi-materi fisika lainnya.

Berdasarkan latar belakang yang telah dipaparkan, maka perlu untuk dilakukan analisis miskonsepsi siswa pada materi dinamika gerak. Hasil penelitian ini dapat digunakan sebagai referensi dan acuan bagi perbaikan sistem pembelajaran baik bagi guru, sekolah ataupun pendidikan pada umunya.

\section{Bahan dan Metode}

Penelitian ini dilakukan di SMA Negeri Plus Provinsi Riau pada bulan Juni hingga September 2017. Jenis penelitian yang diterapkan adalah penelitian survei dengan subjek yang diteliti yaitu seluruh siswa kelas XII yang berjumlah 85 siswa. Instrumen penelitian ini berupa soal tes diagnostik pilihan ganda tiga tingkat (three-tier multiple choice) yang berjumlah 30 butir soal. Setiap butir soal terdiri dari tiga tingkatan. Tingkat satu merupakan soal biasa dengan beberapa opsi jawaban. Tingkat dua berisi beberapa pilihan alasan, disediakan pula tempat kosong untuk siswa menulis alasan secara bebas. Sedangkan tingkat tiga berupa indeks tingkat keyakinan siswa dalam menjawab soal menggunakan skala CRI berdasarkan penelitian Hasan, et al., (1999) seperti terlihat pada Tabel 1. Keyakinan tergolong tinggi jika indeks CRI lebih dari 2,5 dan rendah jika lebih kecil dari 2,5 (Hasan, et al, 1999). 
Tabel 1 Skala Certainly of Response Indeks (CRI)

\begin{tabular}{clc}
\hline Skala & \multicolumn{1}{c}{ Deskripsi } & \multicolumn{1}{c}{ Keterangan } \\
\hline 0 & Jika menjawab soal 100 \% ditebak & Totally Guessed Answer \\
1 & $\begin{array}{l}\text { Jika menjawab soal persentase unsur tebakan antara } \\
75 \%-99 \%\end{array}$ & \multicolumn{1}{c}{ Almost Guess } \\
2 & $\begin{array}{l}\text { Jika dalam menjawab soal persentase unsur tebakan } \\
\text { antara } 50 \%-74 \%\end{array}$ & Not Sure \\
3 & $\begin{array}{l}\text { Jika dalam menjawab soal persentase unsur tebakan } \\
\text { antara 25\%-49\% }\end{array}$ & \multicolumn{1}{c}{ Sure } \\
4 & $\begin{array}{l}\text { Jika dalam menjawab soal persentase unsur tebakan } \\
\text { antara 1\%-24\% } \\
5\end{array}$ & $\begin{array}{l}\text { Jika dalam menjawab soal tidak ada unsur tebakan } \\
\text { sama sekali }(0 \%)\end{array}$ \\
\hline
\end{tabular}

Sumber: Hasan, et al., (1999)

Tabel 2 Interpretasi hasil tes diagnostik pilihan ganda tiga tingkat

\begin{tabular}{lccc}
\hline Kategori & Jawaban & Alasan & Keyakinan (CRI) \\
\hline Paham Konsep & Benar & Benar & Tinggi \\
Tidak Paham Konsep & Benar & Benar & Rendah \\
& Benar & Salah & Rendah \\
& Salah & Benar & Rendah \\
& Salah & Salah & Rendah \\
Miskonsepsi & Salah & Salah & Tinggi \\
& Salah & Benar & Tinggi \\
& Benar & Salah & Tinggi \\
\hline
\end{tabular}

Sumber: Pesman dan Erylmas (2010).

Analisis data diawali dengan penilaian pada setiap jawaban siswa. Berdasarkan jawaban tersebut dilakukan interpretasi pemahaman siswa untuk setiap konsep yang ditanyakan pada soal. Ketentuan interpretasi jawaban siswa diadaptasi dari penelitian Pesman dan Erylmas (2010) seperti terlihat pada Tabel 2.

Tabel 3 Kriteria miskonsepsi

\begin{tabular}{cc}
\hline $\begin{array}{c}\text { Kriteria Miskonsepsi } \\
(\mathbf{\%})\end{array}$ & Tingkat \\
\hline $0<$ Miskonsepsi $\leq 30$ & Rendah \\
$30<$ Miskonsepsi $\leq 70$ & Sedang \\
$70<$ Miskonsepsi $\leq 100$ & Tinggi
\end{tabular}

Sumber: Yudi Kurniawan \& Andi Suhandi (2015).
Tahap selanjutnya adalah perhitungan persentase jumlah siswa yang mengalami miskonsepsi pada setiap konsep/butir soal. Kemudian dilakukan perhitungan persentase rata-rata jumlah siswa yang mengalami miskonsepsi pada materi dinamika gerak secara keseluruhan. Ketentuan tingkat miskonsepsi siswa terlihat pada Tabel 3.

\section{Hasil dan Pembahasan}

Berdasarkan analisis deskriptif data hasil tes diagnostik, diperoleh persentase miskonsepsi siswa sebagaimana terlihat pada Tabel 4. Secara keluruhan, persentase siswa yang mengalami miskonsepsi pada materi dinamika gerak adalah $54.71 \%$. Dengan kata lain, tingkat miskonsepsi siswa berada pada kategori sedang. 
Tabel 4. Persentase siswa yang miskonsepsi pada materi dinamika gerak

\begin{tabular}{|c|c|c|}
\hline Materi Pokok & Topik & \% Miskonsepsi \\
\hline \multirow{11}{*}{$\begin{array}{l}\text { Gaya dan Hukum- } \\
\text { Hukum Newton }\end{array}$} & Gaya-gaya pada benda diam & 60.00 \\
\hline & Gaya-gaya pada benda yang bergerak & 62.35 \\
\hline & Gaya normal & 43.53 \\
\hline & $\begin{array}{l}\text { Arah kecepatan linier pada benda yang bergerak } \\
\text { melingkar }\end{array}$ & 58.82 \\
\hline & Gaya gesek pada benda diam & 80.00 \\
\hline & Penerapan Hukum II Newton & 71.76 \\
\hline & Hubungan massa dan percepatan & 38.82 \\
\hline & Gaya-gaya pada benda yang bergerak melingkar & 41.18 \\
\hline & Faktor yang mempengaruhi gaya gesek & 74.12 \\
\hline & Pasangan gaya aksi-reaksi & 58.82 \\
\hline & Pasangan gaya aksi-reaksi & 37.65 \\
\hline Rata-rata persentase & & 57.01 \\
\hline \multirow{3}{*}{$\begin{array}{l}\text { Hukum Newton } \\
\text { tentang gravitasi }\end{array}$} & Gaya gravitasi antara dua benda & 78.82 \\
\hline & $\begin{array}{l}\text { Hubungan massa dan waktu pada gerak jatuh bebas } \\
\text { benda }\end{array}$ & 75.29 \\
\hline & $\begin{array}{l}\text { Hubungan jari-jari Bumi dengan massa dan berat } \\
\text { benda }\end{array}$ & 52.94 \\
\hline Rata-rata persentase & & 69.02 \\
\hline \multirow{5}{*}{ Usaha dan energi } & Hubungan usaha dan perpindahan & 70.59 \\
\hline & $\begin{array}{l}\text { Perbandingan energi kinetik benda yang jatuh bebas } \\
\text { dan diberi kecepatan horizontal }\end{array}$ & 56.47 \\
\hline & Energi pada benda yang diam & 38.82 \\
\hline & Hubungan usaha dan energi & 41.18 \\
\hline & Hukum kekekalan energi mekanik & 38.82 \\
\hline Rata-rata persentase & & 49.18 \\
\hline \multirow{2}{*}{$\begin{array}{l}\text { Elastisitas dan } \\
\text { hukum Hooke }\end{array}$} & Hukum hooke berdasarkan grafik & 49.41 \\
\hline & Pengaruh modulus young pada elastisitas & 47.06 \\
\hline Rata-rata persentase & & 48.24 \\
\hline \multirow{5}{*}{$\begin{array}{l}\text { Momentum, } \\
\text { impuls, dan } \\
\text { tumbukan }\end{array}$} & Konsep momentum & 50.59 \\
\hline & Konsep impuls & 68.24 \\
\hline & Hubungan momentum dan impuls & 57.65 \\
\hline & Hukum kekekalan momentum & 67.06 \\
\hline & Tumbukan lenting sempurna & 55.29 \\
\hline Rata-rata persentase & & 59.77 \\
\hline
\end{tabular}




\begin{tabular}{|c|c|c|}
\hline Materi Pokok & Topik & \% Miskonsepsi \\
\hline \multirow{4}{*}{$\begin{array}{l}\text { Keseimbangan dan } \\
\text { dinamika rotasi }\end{array}$} & Konsep torsi & 47.06 \\
\hline & Konsep momen inersia & 42.35 \\
\hline & Hukum kekekalan momentum sudut & 57.65 \\
\hline & Syarat kesetimbangan & 18.82 \\
\hline \multicolumn{2}{|l|}{ Rata-rata persentase } & 41.47 \\
\hline \multicolumn{2}{|c|}{ Rata-rata persentase keseluruhan } & 54.71 \\
\hline
\end{tabular}

\section{Gaya dan hukum-hukum Newton}

Rata-rata persentase siswa yang mengalami miskonsepsi pada materi pokok Gaya dan Hukum-Hukum Newton adalah sebesar $57.01 \% \quad$ (kategori sedang). Miskonsepsi tertinggi terjadi pada konsep gaya gesek pada benda yang diam yaitu sebesar $80 \%$. Bentuk soal yang disajikan adalah:

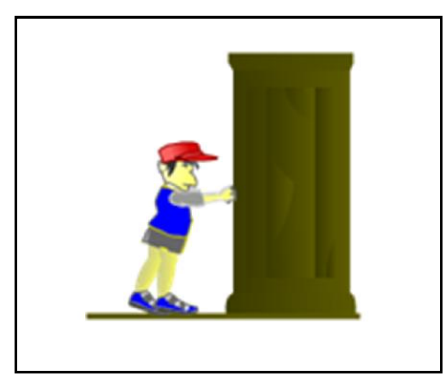

Perhatikan gambar!

Gagas mendorong sebuah lemari di atas lantai kasar, namun lemari tersebut tidak bergerak sama sekali. Manakah pernyataan yang benar tentang peristiwa ini?

A. Gaya dorong < gaya gesekan lemari dan lantai

B. Gaya dorong $>$ gaya gesekan lemari dan lantai

C. Gaya dorong = gesekan lemari dan lantai

D. Gaya dorong $\leq$ gaya gesekan lemari dan lantai

Alasan ...

A. Berlaku hukum I Newton; resultan gaya gesek dan gaya dorong adalah 0

B. Berlaku hukum II Newton; percepatan pada lemari sangat kecil

C. Berlaku hukum II Newton; gaya gesek belum mencapai gaya gesek statis maksimum

D. Berlaku hukum III Newton; merupakan pasangan gaya aksi reaksi

E. ...
Sebagian besar siswa menjawab gaya dorong < gaya gesekan lemari dan lantai dan gaya dorong $\leq$ gaya gesekan lemari dan lantai. Hal ini karena siswa beranggapan bahwa gaya dorong yang diberikan orang sangat kecil sehingga tidak cukup membuat lemari bergerak. Padahal jika gaya dorong lebih kecil dari gaya gesekan maka lemari akan bergerak berlawanan arah dengan gaya dorong (hal ini tidak terjadi). Oleh sebab itu pada kasus ini berlaku hukum I Newton, yaitu resultan gaya yang bekerja antara orang dan lemari harus 0 . Artinya gaya dorong sama dengan gaya gesekan lemari dan lantai.

\section{Hukum Newton tentang gravitasi}

Rata-rata persentase siswa yang mengalami miskonsepsi pada materi pokok hukum Newton tentang gravitasi adalah sebesar 69.02\% (kategori sedang). Miskonsepsi tertinggi terjadi pada konsep gaya gravitasi antara dua benda dengan persentase sebesar $78.82 \%$. Bentuk soal yang disajikan adalah:

Mr. Newon sedang duduk di bawah pohon apel. Tiba-tiba sebuah apel mengenai kepalanya dan jatuh ke tanah. Pernyataan yang benar tentang peristiwa ini adalah...

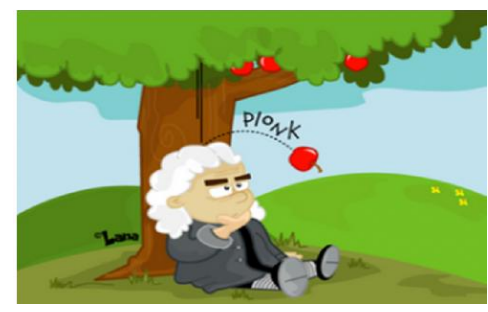

A. Gaya tarik Bumi pada apel $>$ gaya tarik apel pada Bumi

B. Gaya tarik Bumi pada apel = gaya tarik apel pada Bumi 
C. Gaya tarik Bumi pada apel $<$ gaya tarik apel pada Bumi

D. Gaya tarik Bumi pada apel $\geq$ gaya tarik apel pada Bumi

Alasan ...

A. Massa Bumi lebih besar daripada massa apel, sehingga Bumi memiliki kelembaman yang lebih besar

B. Medan gravitasi Bumi lebih besar atau sama dengan medan gravitasi apel

C. Medan gravitasi Bumi lebih besar daripada medan gravitasi apel, sehinga apel jatuh ke Bumi

D. Merupakan pasangan gaya aksi-reaksi, besarnya sebanding dengan massa Bumi dan apel

E. $\ldots$

Sebagian besar siswa beranggapan bahwa gerakan apel yang jatuh ke Bumi (bukan Bumi yang jatuh ke Apel) terjadi karena gaya tarik Bumi pada apel $>$ gaya tarik apel pada Bumi. Siswa semakin yakin dengan pilihan jawaban ini karena pada soal disediakan pilihan alasan bahwa massa Bumi lebih besar daripada massa apel, sehingga Bumi lebih lembam dan medan gravitasi Bumi lebih besar daripada medan gravitasi apel. Siswa tidak memahami bahwa gaya tarikmenarik yang terjadi pada Bumi dan apel adalah pasangan gaya aksi-reaksi. Pasangan gaya aksi-reaksi selalu memiliki nilai yang sama besar namun arahnya berlawanan. Oleh karena itu jawaban yang tepat untuk soal ini adalah gaya tarik Bumi pada apel = gaya tarik apel pada Bumi, karena merupakan pasangan gaya aksi-reaksi, besarnya sebanding dengan massa Bumi dan apel.

\section{Usaha dan energi}

Jumlah siswa yang mengalami miskonsepsi pada materi pokok usaha dan energi berada pada kategori sedang dengan persentase rata-rata sebesar 49.18\%. Miskonsepsi tertinggi terjadi pada konsep hubungan usaha dan perpindahan sebesar $70.59 \%$. Bentuk soal yang disajikan adalah:

Perhatikan gambar

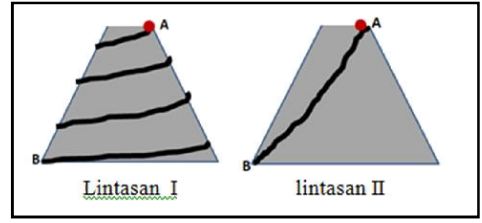

Sebuah benda meluncur menuruni suatu gundukan dari titik A ke titik B menggunakan dua bentuk lintasan seperti pada gambar. Jika lintasan dianggap licin, pernyataan yang benar adalah ...

A. Usaha benda melalui lintasan I > usaha benda melalui lintasan II

B. Usaha benda melalui lintasan I < usaha benda melalui lintasan II

C. Usaha benda melalui lintasan I = usaha benda melalui lintasan II

D. Total energi benda melalui lintasan I > Total energi melalui lintasan II Alasan ...

A. Lintasan I lebih panjang

B. Perpindahan yang dialami benda sama besar

C. Waktu tempuh benda melalui lintasan I lebih lama

D. Lintasan 1 lebih landai

Sebagian besar siswa meyakini bahwa usaha benda melalui lintasan I lebih besar dari usaha benda melalui lintasan II dengan dua alasan yang berbeda. Pertama, karena lintasan pertama lebih panjang. Kedua, karena waktu tempuh dengan lintasan I lebih lama. Dalam hal ini siswa tidak memahami bahwa faktor yang mempengaruhi usaha yang dilakukan suatu benda bukanlah jarak, waktu atau bentuk lintasan yang dialami suatu benda, melainkan gaya dan perpindahan. Pada kasus ini hanya gaya berat yang bekerja pada benda, sehingga usaha yang dimaksudkan pada soal adalah usaha oleh gaya berat. Perpindahan yang mempengaruhi besarnya usaha benda hanya pada sumbu vertikal, sebab pada arah horizontal arah perpindahan tegak lurus terhadap gaya berat yang menghasilkan usaha bernilai 0 . Karena gaya dan perpindahan yang dialami benda dengan kedua bentuk lintasan sama besar, maka jawaban yang tepat adalah usaha benda melalui lintasan I = usaha benda melalui lintasan II karena perpindahan yang dialami benda sama besar.

\section{Elastisitas dan hukum Hooke}

Jumlah siswa yang mengalami miskonsepsi pada materi pokok elastisitas dan hukum Hooke berada pada kategori sedang dengan rata-rata persentase sebesar $48.24 \%$. Miskonsepsi tertinggi terjadi pada saat menentukan konstanta pegas berdasarkan 
grafik yaitu sebesar $49.41 \%$. Bentuk soal yang disajikan adalah:

Pada suatu percobaan seorang siswa ingin menentukan konstanta pegas empat karet gelang yang berbeda. Setiap kali beban ditambah ia selalu mencatat perubahan panjang karet yang sedang diukurnya. Dari data-data tersebut diperoleh grafik F-x sebagai berikut.

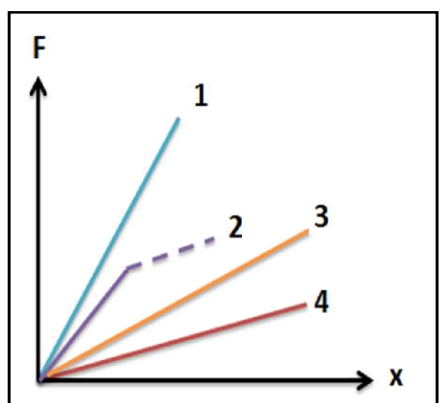

Berdasarkan grafik di atas, karet gelang manakah yang memiliki konstanta pegas paling kecil?
A. 1
B. 2
C. 3
D. 4

Alasan ...

A. Paling sulit diregangkan, dengan gaya yang sama karet mengalami pemanjangan paling kecil

B. Paling sulit diregangkan, dengan gaya yang sama karet paling sulit putus

C. Paling mudah diregangkan, dengan gaya yang sama karet paling mudah putus

D. Paling mudah diregangkan, dengan gaya yang sama karet mengalami pemanjangan paling besar

E. $\cdots$

Sebagian besar siswa menjawab karet 1 memiliki konstanta pegas paling kecil. Alasan yang dipilih adalah karena karet tersebut paling sulit diregangkan, dengan gaya yang sama karet 1 mengalami pemanjangan paling kecil. Sebagian siswa yang lain menjawab pegas 2 memiliki konstanta pegas paling kecil karena karet mudah diregangkan dan mudah putus. Hal ini menunjukkan bahwa siswa tidak memahami makna fisis dari konstanta pegas. Konstanta pegas menunjukan kecenderungan benda untuk mempertahankan ukurannya ketika diberi gaya luar. Semakin kecil konstanta pegasnya, maka semakin mudah mengubah ukuran benda tersebut. Berdasarkan grafik tersebut, dapat dilihat bahwa karet yang memiliki konstanta pegas terkecil adalah karet 4 karena karet paling mudah diregangkan, dengan gaya yang sama karet mengalami pemanjangan paling besar.

\section{Momentum, impuls, dan tumbukan}

Pada materi pokok momentum, impuls, dan tumbukan rata-rata persentase siswa yang mengalami miskonsepsi berada pada kategori sedang yaitu sebesar 59.77\%. Miskonsepsi tertinggi terjadi pada konsep impuls yaitu sebesar $68.24 \%$ Bentuk soal yang disajikan adalah:

Dalam suatu pertandingan, seorang petinju akan memukul lawannya. Agar efek pukulan terasa lebih besar, maka yang harus dilakukan oleh petinju adalah ...

A. Memperpanjang waktu kontak pukulan

B. Mempersingkat waktu kontak pukulan

C. Memperbesar jarak pukulan

D. Memperbesar kepalan tangan

Alasan ...

A. Agar diperoleh usaha yang besar

B. Agar diperoleh gaya kontak yang besar

C. Agar diperoleh impuls yang besar

D. Agar diperoleh momentum yang besar

E. $\ldots$

Soal ini menguji siswa untuk memahami konsep impuls. Untuk memperbesar efek pukulan yang diterima lawan, maka yang diharapkan adalah petinju dapat memperbesar gaya kontaknya. Hal ini dapat dilakukan dengan mempersingkat waktu kontak pukulan. Miskonsepsi yang terjadi hampir merata pada semua pilihan jawaban. Sebagian siswa beranggapan bahwa dengan mempersingkat waktu kontak, maka impuls yang terjadi menjadi lebih besar. Padahal implus berbanding lurus terhadap waktu kontak. Sebagian siswa yang lain menganggap dengan mempersingkat waktu kontak dan memperbesar jarak pukulan akan menyebab-kan momentum menjadi lebih besar. Padahal momentum yang terjadi pada benda tidak berhubungan dengan waktu kontak ataupun jarak. 


\section{Keseimbangan dan dinamika rotasi}

Pada materi pokok keseimbangan dan dinamika rotasi terlihat bahwa rata-rata persentase siswa yang mengalami miskonsepsi berada pada kategori sedang yaitu sebesar 41.47\%. Miskonsepsi tertinggi terjadi pada butir topik hukum kekekalan momentum yaitu sebesar $57.65 \%$. Bentuk soal yang disajikan adalah:

Seorang penari balet mula-mula berputar dengan merentangkan tangannya. Tiba-tiba ia merapatkan tangan ke tubuhnya. Bila gesekan udara diabaikan, bagaimanakah putaran penari tersebut?
A. Lebih cepat
B. Lebih lambat
C. Tetap
D. Tetap atau lebih cepat Alasan ...

A. Momentum sudut tetap

B. Momentum sudut bertambah

C. Momentum sudut berkurang

D. Tidak ada pengaruh tangan terhadap putaran penari $\ldots$

Konsep yang diyakini oleh sebagian besar siswa adalah putaran penari setelah merapatkan tangannya menjadi lebih cepat karena momentum sudut orang tersebut berkurang. Sebagian yang lain menjawab putaran penari menjadi lebih cepat karena momentum sudut bertambah. Sebagian siswa yang lain lagi menjawab putaran penari menjadi lebih lambat karena siswa menganggap momentum sudut penari tersebut berkurang. Ini merupakan konsepsi-konsepsi yang salah. Momentum sudut bersifat kekal jika tidak ada gaya dan torsi luar yang mempengaruhi. Saat penari merapatkan tangannya, maka jari-jari putaran menjadi lebih kecil, sehingga momen inersia penari juga menjadi lebih kecil. Karena momentum sudut kekal, maka secara otomatis kecepatan sudut akan bertambah. Oleh karena itu jawaban yang tepat untuk soal ini adalah putaran penari menjadi lebih cepat karena momentum sudut tetap.

$$
\text { Taber dalam Hunson }
$$
mengatakan bahwa jika lebih dari 10\% siswa dari suatu penelitian mengalami miskonsepsi pada suatu konsep, maka harus diberikan perhatian lebih serta perlakukan khusus untuk mengatasinya. Berdasarkan hasil penelitian diperoleh bahwa miskonsepsi yang terjadi pada setiap konsep mencapai angka-angka di atas $10 \%$. Maka dari itu sangat perlu dilakukan tindak lanjut untuk mengatasi permasalahan ini.

Miskonsepsi dapat terjadi karena berbagai faktor. Faktor-faktor ini bisa berasal dari guru, buku, metode pembelajaran, dan dari siswa sendiri (Paul Suparno, 2013). Berdasarkan pengamatan dan wawancara singkat dengan beberapa siswa diperoleh informasi bahwa pembelajaran masih terfokus kepada guru daripada siswa. Metode ceramah adalah metode yang paling sering dipakai di kelas, sedangkan siswa hanya menerima informasi dari guru. Hal ini bisa menjadi salah satu sebab munculnya miskonsepsi siswa.

\section{Kesimpulan dan Saran}

Berdasarkan penelitian yang telah dilakukan dapat disimpulkan bahwa tingkat miskonsepsi siswa kelas XII SMAN Plus Provinsi Riau berada pada kategori sedang dengan rata-rata persentase siswa yang mengalami miskonsepsi secara keseluruhan sebesar $54.71 \%$.

Berdasarkan kesimpulan tersebut, maka peneliti merekomendasikan agar guru dapat mengembangkan strategi pembelajaran yang sesuai guna mengatasi miskonsepsi pada siswa. Strategi yang digunakan diharapkan dapat memeberikan penekanan pada pemahaman konsep daripada persamaan matematis saja. Bagi peneliti lain yang akan melakukan penelitian serupa, penelitian ini dapat dilengkapi dengan kegiatan wawancara kepada sumber-sumber terkait seperti guru dan siswa untuk memperoleh informasi secara lengkap mengenai penyebab terjadinya miskonsepsi pada siswa.

\section{Daftar Pustaka}

Asep Dedy Sutrisno, 2014. Penggunaan Model Pembelajaran Two Stay Two Stray (TSTS) Berbantuan Simulasi Komputer untuk Meminimalisasi Miskonsepsi pada Materi Momentum dan Impuls. 
Universitas Pendidikan Indonesia. repository.upi.edu, Bandung.

Dindar, A.C \& Geban, O., 2011. Development of three-tier test to asses high school Students understanding of acid and bases. Procedia social and behavioral sciences, 115 , pp. 600-604.

Hasan, S., Bagokayo, D., \& Kelley, E.L., 1999. Misconceptions and the Certainty of Response Index (CRI). Physic Education Journal, 34 (5), 294-299.

Hunson, Ruby, 2015. Identifying Students' Alternative Concepts in Basic Chemical Bonding - A Case Study of Teacher Trainees in the University of Education, Winneba. International Journal of Innovtive Research and Development, 4(1), 115-122.

Izza Auliyatul Muna, 2015. Identifikasi Miskonsepsi Mahasiswa PGMI Pada Konsep Hukum Newton Menggunakan Certainty of Response Index (CRI). Jurnal Cendikia, 13(2), 309-322.

Luh Sukariasih, 2016. The Use of Cognitive Conflict Strategy to Reduce Student Misconceptions on the Subject Matter of Rectilinear Motion. International
Journal of Education and Research, 4(7), 483-492.

Oberoi, Manmeet, 2017. Review of Literature on Student's Misconceptions in Science. International Journal of Scientific Research and Education, 5(3), 62746280.

Paul Suparno, 2013. Miskonsepsi dan Perubahan Konsep pada Pendidikan Fisika. Grasindo, Jakarta.

Pesman, Haki \& Eryilmas, Ali, 2010. Development of Three-tier Test to Asses Misconception about Simple Electric Circuits. The journal of Educational Research, 103, 208-222.

Suwarto, 2013. Pengembangan Tes Diagnostic Dalam Pembelajaran. Pustaka Pelajar,Yogyakarta.

Tuysuz, C., 2009. Development of Two-tier Diagnostic Instrument and Asses Students: Understanding in Chemistry. Scientific Research and Essay, 4 (6), 626-631.

Yudi Kurniawan \& Andi Suhandi. 2015. The Three-tier Test for Identification the Quality of Students' Misconception on Newton's First Law. Full Paper Prociding GTAR-2015, 2, 313-319. 